\title{
What provokes experienced COPD clinical practitioners in the UK to initiate or change medication? A consensus study
}

\section{Jane Upton ${ }^{a}$, Ellen McCutcheon ${ }^{a}$, Christine Loveridge $^{a}, J^{\prime}$ hn Wiggins ${ }^{b}$, Samantha Walker, *Monica Fletcher ${ }^{\mathrm{a}}$}

\author{
a Education for Health, Warwick, Warwickshire, UK \\ ${ }^{\mathrm{b}}$ Consultant Chest Physician, Wexham Park Hospital, Slough, UK
}

Received 28th June 2010; revised 22nd October 2010; accepted 12th November 2010; online 8th March 2011

\begin{abstract}
Background: In the absence of clarity in national guidelines, this study aimed to reach a consensus among experts in chronic obstructive pulmonary disease (COPD) regarding when medication should be initiated or changed in patients demonstrating a gradual decline.

Methods: An electronic three-stage Delphi exercise was undertaken with 37 leading UK experts in COPD. The panel submitted criteria which they scored in subsequent rounds. Consensus was defined as $\geq 80 \%$ of the panel scoring an item as important.

Results: Consensus was reached on seven criteria: decreased exercise tolerance (97\%); increased breathlessness at rest or on exertion $(97 \%)$; quality of life impairment $(91 \%)$; low or reduced oxygen saturations based on pulse oximetry readings ( $86 \%)$; ability to perform activities of daily living independently (85\%); increase in sputum (80\%); and increase in wheeze $(80 \%)$.

Conclusions: These criteria could be used to guide clinical practice. Empirical research is now required to test their reliability and validity.

(C) 2011 Primary Care Respiratory Society UK. All rights reserved.

J Upton et al. Prim Care Respir J 2011; 20(2): 155-160

doi: $10.4104 /$ pcrj.2011.00008
\end{abstract}

Keywords chronic obstructive pulmonary disease, medication, consensus

See linked editorial by Yawn on pg 111

The full version of this paper, with online Appendices 1

and 2 , is available at www.thepcrj.org

\section{Introduction}

Chronic obstructive pulmonary disease (COPD) is characterised by airflow obstruction, which is usually progressive. Respiratory symptoms include breathlessness on exertion, chronic cough, regular sputum production, frequent winter 'bronchitis' and wheeze. ${ }^{1}$ Although COPD is a preventable and treatable disease, ${ }^{2}$ worldwide it is the seventh leading cause of lost Disability Adjusted Life Years and is projected to rank fifth in 2030. ${ }^{3}$ The burden of COPD on the healthcare system in the UK is high. ${ }^{4}$ It has been estimated that the annual direct cost of COPD in the UK is $f 819$ per patient, which is 2.5 times higher than the estimated direct cost per patient of asthma. ${ }^{5}$ As these high costs are mainly due to emergency unscheduled care, the burden of COPD may therefore be reduced by increasing the proportion of patients receiving effective care in scheduled consultations. $^{5}$

In the UK the majority of care of people with COPD is managed by a range of healthcare professionals in the primary care setting. The expectation is that treatment decisions will be based on either national or international guidelines. The National Institute for Health and Clinical Excellence (NICE) guidelines for COPD' recommend that the assessment of COPD should take into account the presence of symptoms, clinical signs, the results of spirometry, and the frequency of exacerbations. The guidelines further recommend that medication should be initiated or changed in 'patients who remain symptomatic'. Similarly, the Global Initiative for Chronic Obstructive Lung Disease guidelines, ${ }^{2}$ developed through a series of consensus meetings, state that symptoms and objective measures of airflow limitation should be monitored to determine when to modify therapy. Neither guideline specifies exactly which criteria

\footnotetext{
* Corresponding author: Mrs Monica Fletcher, Education for Health, 10 Church Street, Warwick, Warwickshire, CV34 4AB, UK Tel: +44 (0)1926 493313 E-Mail: m.fletcher@educationforhealth.org
} 
clinicians might use to determine whether a patient is 'symptomatic'. This may lead to both uncertainty and variations in clinical practice, as guidelines are most likely to be followed when they are easy to understand. ${ }^{6}$

The primary aim of this study was to reach a consensus among experts in COPD regarding the criteria that would aid decision-making when initiating or changing COPD medication in patients who are increasingly becoming chronically symptomatic but who have not experienced an acute exacerbation. These criteria would inform future empirical research and, in turn, clarify national guidelines. A secondary aim was to explore whether this consensus could include the views of primary and secondary care clinicians or whether these need to be considered separately.

\section{Methods}

\section{Participants}

Participants were an expert panel of experienced primary and hospital healthcare prescribers of COPD medication (nurses, doctors and pharmacists) who were either members of a national COPD guideline committee (listed in Appendix 1, available online at www.thepcrj.org) or were identified by at least one guideline committee member as being a specialist in COPD. They were recruited from both primary and hospital care health settings to ensure that the list of important criteria to consider when changing or initiating COPD medication was applicable across a range of disease severities.

In keeping with other similar studies, ${ }^{7,8}$ ethical approval was not needed for this study as participants were clinicians recruited from national guideline committees.

There is no agreed definition of when consensus has been reached using the Delphi method. We therefore selected the common criteria of consensus of a prespecified percentage of the panel agreeing that a sign or symptom is important. ${ }^{9}$ More specifically, consensus was defined a priori as at least $80 \%$ of the expert panel scoring an item as 4 or 5 on a 5 point scale ranging from 1 (least important to consider) to 5 (most important to consider). This high percentage level was chosen as it has previously been suggested that $75 \%$ is the minimum level; ${ }^{10}$ also, because this topic is important and directly related to patient care, we were keen that the results of this Delphi study only included those criteria that most of the expert panel agreed should be considered.

\section{Delphi process}

A three-stage electronic Delphi study ${ }^{9}$ was undertaken between March and July 2009 using an online survey tool (http://www.surveymonkey.com/). This involved three electronic questionnaires which were completed quasianonymously by panel members (i.e. responses were known to the researcher but not to other panel members). After each round the data were aggregated at group level and structured feedback was given to the panel.

This methodology was used as it provides a useful way of identifying and measuring uncertainty in medical and health services research, and provides a means of harnessing the insights of appropriate experts where published information is inadequate. ${ }^{11}$ The Delphi method has the advantage over group consensus methods such as the nominal group technique of allowing responses to be quasi-anonymous. This enables panel members to develop their viewpoint through reflection on the data obtained in the previous round, rather than being swayed by dominant members of the group. However, a danger of this quasi-anonymity is that it may lead to lack of accountability of views, although this is unlikely when panel members are experts in their field..$^{12}$ The Delphi method is also less likely than group consensus methods to result in 'risky-shifts' (extreme views developed through the process of discussion of the topic as a group). ${ }^{13}$ It also has the very practical advantage that it avoids the logistical challenges of bringing together a large group of experts in one place.

\section{Round 1}

In this round a list of relevant signs and symptoms was obtained by requesting panel members to 'list the signs and symptoms you think should prompt the initiation or change of treatment in a routine COPD consultation'. In order not to be too restrictive at this stage of the Delphi process, no further instructions were given and the term 'treatment' was not defined. The submitted signs and symptoms were collated and then categorised into groups of related criteria by the clinical advisory group (two primary care nurses with expertise in COPD and a hospital respiratory physician). The clinical advisory group also identified similar criteria that had been described using different terminology. These were collated under the most commonly used term; otherwise the exact terms used by panel members were included in Round 2. Criteria that the clinical advisory group advised would not directly lead to the initiation or change of pharmacological treatment were excluded from Round 2. Also, as this study aimed to investigate changes in the treatment of routine COPD consultations rather than as a result of exacerbations, signs and symptoms that directly related to exacerbations were also excluded by the clinical advisory group.

\section{Round 2}

In this round a questionnaire was devised using data from Round 1 and electronically sent to the panel. The panel were requested to 'score signs/symptoms highly that you think a generalist clinician should normally consider when initiating or changing COPD medication (irrespective of other symptoms or co-morbidities that might be present in individual patients)'. They were also requested to 'tailor your answers to a routine follow-up consultation - i.e. not following an exacerbation'. The expert panel scored the 
criteria on a 5-point Likert scale (1=least important, $5=$ most important). The order of the criteria was randomised between subjects to prevent a question-ordering effect. Panel members were invited to write questions and comments on the questionnaire.

\section{Round 3}

In this round the questionnaire was refined based on the data from the previous round. The descriptive quantitative data, together with questions and comments submitted in the previous round, were electronically sent to the panel. They were also notified of any changes made to the questionnaire items as a result of the panel's comments. Lastly, each panel member was reminded of the score they gave in Round 2 for each sign or symptom. The panel member was requested to read the results of Round 2 and then complete the Round 3 questionnaire. The instructions for completion of the Round 3 questionnaires were the same as for Round 2.

Up to two reminder emails prompting completion were sent after three weeks to panel members who had not responded. Each round was closed after four weeks.

\section{Results}

The final panel consisted of 37 COPD experts; 21 of 33 national COPD guideline committee members accepted our invitation to participate (response rate $64 \%$ ) while 16 of the 21 COPD experts identified by a guideline committee member accepted the invitation (response rate 76\%). Thirty-seven COPD experts completed Round 1, 35 completed Round 2,

Table 1. Distribution of panels' scores following Round $3(n, \%)$.

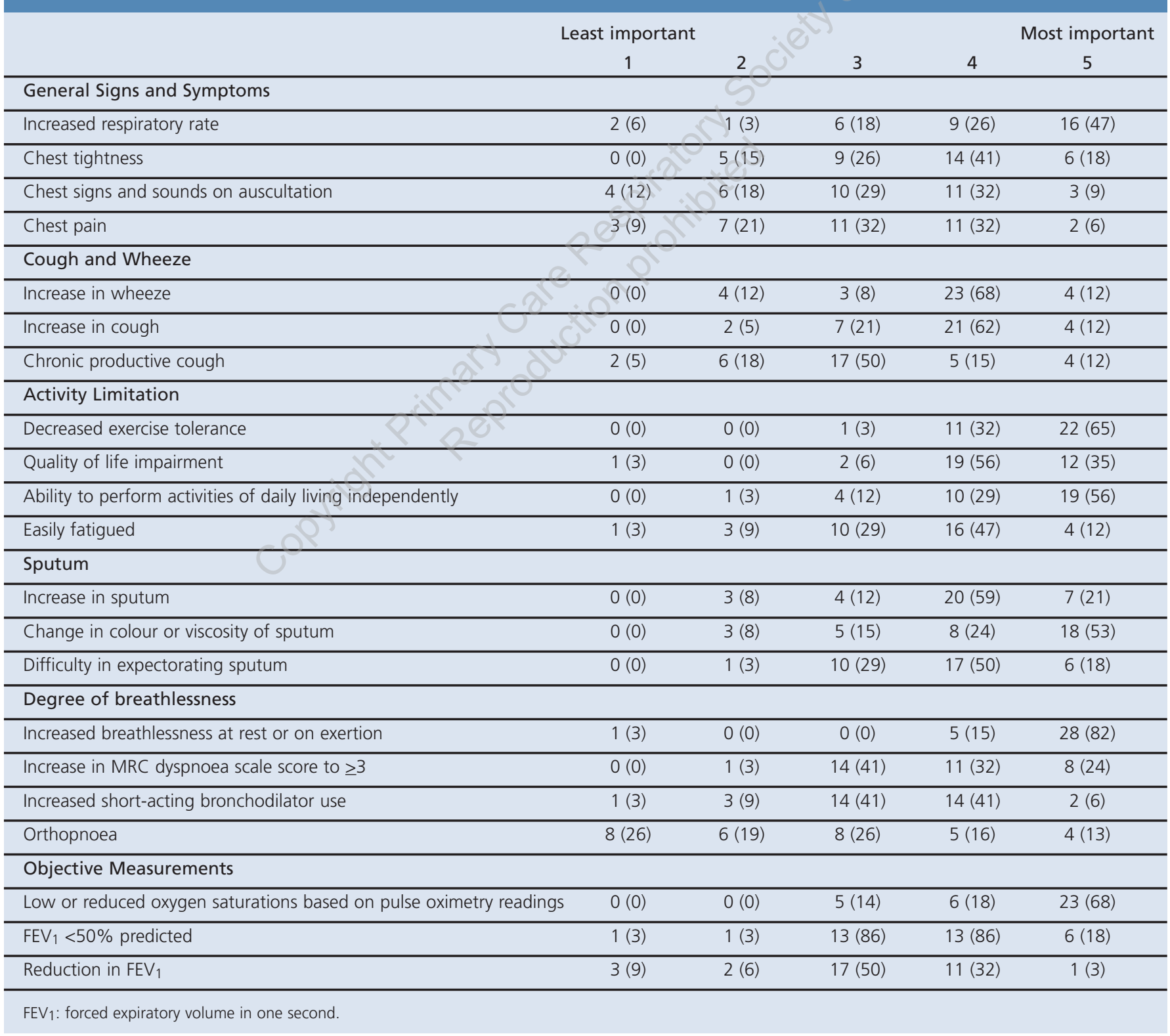


and 34 completed all three rounds (92\% completion rate). Eighteen of these 34 were based in primary care (12 doctors and six nurses) and 16 were hospital-based (seven doctors, eight nurses and one pharmacist).

\section{Results of the rounds}

\section{Criteria included in rounds}

Panel members submitted 99 criteria in the first round. These were grouped into six broad categories of relevant criteria by the clinical advisory group: general signs and symptoms; cough and wheeze; activity limitation; sputum; objective measures; and degree of breathlessness. The clinical advisory group excluded criteria not directly related to initiating or changing specific COPD treatment of patients (these are listed in online Appendix 2). The clinical advisory group also excluded similar terms for the same sign or symptom. This resulted in 25 criteria being included in the Round 2 questionnaire. These criteria were commented on by the panel, resulting in the number of criteria included in Round 3 being reduced to 21 .

The distribution of the panel's scores for each of the criteria is shown in Table 1. The panel reached a consensus that seven of these criteria were important to consider when initiating or changing medication in COPD patients who are demonstrating a gradual decline (Table 2). The attributed importance of the remaining symptoms is shown separately for primary and hospital care experts in Table 3.

\section{Discussion}

This study aimed to clarify the national guidelines for COPD by establishing specialist consensus on the criteria that should be considered when initiating or changing respiratory medication in a patient who is demonstrating a gradual decline. The panel

Table 2. Criteria on which consensus was reached (number (\%) of experts who rated a sign or symptom 4 or 5 ).

\begin{tabular}{lccc} 
& $\begin{array}{c}\text { Primary care } \\
\mathrm{n}(\%)\end{array}$ & $\begin{array}{c}\text { Secondary care } \\
\mathrm{n}(\%)\end{array}$ & $\begin{array}{c}\text { Combined } \\
\mathrm{n}(\%)\end{array}$ \\
\hline Increased breathlessness at rest or on exertion & $17(94)$ & $15(100)$ & $33(97)$ \\
\hline Decreased exercise tolerance & $18(100)$ & $14(88)$ & $33(97)$ \\
\hline Quality of life impairment & $17(95)$ & $15(94)$ & $29(91)$ \\
\hline Low or reduced oxygen saturations based on pulse oximetry readings & $14(78)$ & $16(100)$ & $12(75)$ \\
\hline Ability to perform activities of daily living independently & $15(83)$ & $14(87)$ & $27(80)$ \\
\hline Increase in sputum & $13(72)$ & $27(80)$ &
\end{tabular}

Table 3. Criteria on which no consensus was reached (number (\%) of experts who rated sign or symptoms as 4 or 5 ).

\begin{tabular}{|c|c|c|c|}
\hline & $\begin{array}{c}\text { Primary care } \\
\mathrm{n}(\%)\end{array}$ & $\begin{array}{c}\text { Secondary care } \\
\mathrm{n}(\%)\end{array}$ & $\begin{array}{c}\text { Combined } \\
\mathrm{n}(\%)\end{array}$ \\
\hline Change in colour or viscosity of sputum & $12(67)$ & $14(88)$ & $26(77)$ \\
\hline Increase in cough & $13(72)$ & $12(76)$ & $25(74)$ \\
\hline Increased respiratory rate & $14(78)$ & $11(69)$ & $25(73)$ \\
\hline Difficulty expectorating sputum & $12(66)$ & $11(69)$ & $23(68)$ \\
\hline Chest tightness & $8(44)$ & $12(75)$ & $20(59)$ \\
\hline Easily fatigued & $9(50)$ & $11(69)$ & $20(59)$ \\
\hline $\mathrm{FEV}_{1}<50 \%$ predicted & $12(66)$ & $7(44)$ & $19(56)$ \\
\hline Increase in MRC dyspnoea scale score to $\geq 3$ & $11(61)$ & $8(51)$ & $19(56)$ \\
\hline Increased short-acting bronchodilator use & $6(34)$ & $10(62)$ & $16(47)$ \\
\hline Chest signs on auscultation & $7(39)$ & $7(44)$ & $14(41)$ \\
\hline Chest pain & $7(39)$ & $6(38)$ & $13(38)$ \\
\hline Reduction in $\mathrm{FEV}_{1}$ & $8(45)$ & $4(25)$ & $12(35)$ \\
\hline Orthopnoea & $4(26)$ & $5(33)$ & $9(29)$ \\
\hline Chronic productive cough & $5(28)$ & $4(25)$ & $9(27)$ \\
\hline
\end{tabular}

$\mathrm{FEV}_{1}$ : forced expiratory volume in one second. 
reached consensus on seven items: increased breathlessness at rest or on exertion; decreased exercise tolerance; quality of life impairment; low or reduced oxygen saturations based on pulse oximetry readings; ability to perform activities of daily living independently; increase in sputum; and increase in wheeze.

\section{Strengths and limitations of the study}

A major strength of this Delphi exercise is that high response and completion rates were obtained from panel members who were recruited from national COPD committees or put forward by them. The findings are therefore representative of the views of leading primary and hospital care experts in COPD in the UK. As panel members are experts in their field, these views are likely to be based on best evidence; however, they will also be influenced by other factors such as their training and local practice circumstances.

This list of criteria reflects real practice but needs to be investigated in future research studies in order to provide a list of well-defined criteria which clinicians can use in clinical practice when determining if a patient is symptomatic. Future research should also investigate when these changes should be made, and whether these criteria might inform more general changes in the management of COPD or should only be used to guide the prescription of medication.

A strength of this study is that it has facilitated consensus to be reached by leading experts based on their clinical experience. However, a limitation of this methodology is that the validity and reliability of these findings are not known. Further research is therefore required to investigate whether the use of these criteria in assessing patients with COPD improves patient outcomes. Further research should also determine whether all seven criteria should be used, or whether this list can be further reduced without compromising patient care.

\section{Clinical implications}

Most of the criteria agreed by this panel of COPD experts were similar to those identified in the development of the COPD Assessment Test (CAT) ${ }^{14}$ as being important to patients. An exception to this was pulse oximetry. This may have been included by the panel as national guidelines state that oxygen therapy should be assessed in patients with oxygen saturations $\leq 92 \%$ breathing air. ${ }^{1}$

Fourteen signs and symptoms were given a high importance score $(\geq 4)$, but less than $80 \%$ agreed they were important. This lack of consensus illustrates the need to clarify the guidelines. One of these criteria was the performance of spirometry. Clearly spirometry is essential in making the diagnosis of COPD and for classifying the severity of the disease, ${ }^{1}$ but it is noteworthy that it was not included in the final list of criteria agreed by the expert panel for being useful in changing medication. This may reflect the lack of definitive evidence that inhaled corticosteroids (ICS) have any clinically significant effect on the decline in forced expiratory volume in one second $\left(\mathrm{FEV}_{1}\right)$ in COPD patients in the long term. ${ }^{15} \mathrm{NICE}$ guidance states that the aim of treatment with ICS is to slow the decline in health status and not to improve lung function per se. ${ }^{1}$ However, one of the three clinical indicators for the management of COPD included in the Quality Outcomes Framework - which provides financial incentives to general practitioners for the performance of key tasks (http://www.qof.ic.nhs.uk/) - is 'the percentage of patients with COPD with a record of FEV 1 in the previous 15 months'. This suggests that some aspects of the COPD QOF criteria do not reflect guidelines and should be re-considered.

Future policy should address the discrepancy between the criteria that COPD experts agree should be considered and those for which general practices are reimbursed within the QOF. Research is required to determine how the recommendations made by this panel of COPD experts should be implemented in clinical practice.

\section{Conclusion}

Leading experts in COPD reached a consensus on seven criteria that would provoke a decision to initiate or change the pharmacological treatment of patients who are demonstrating a gradual decline. There were also several criteria on which the panel did not reach consensus (e.g. spirometry). This list of criteria reflects real practice but needs to be investigated in future empirical research studies in order to provide a valid and reliable list of well-defined criteria which clinicians can use in clinical practice when determining if a patient is 'symptomatic'.

\section{Acknowledgements}

The authors would like to thank the COPD experts who participated in this study and Sandy Walmsley, Philippa Major and Erica Haines for their support and advice.

\section{Funding}

This study was supported by an unrestricted educational grant from BoehringerIngelheim. The study sponsors did not have any role in the study design, in the collection, analysis and interpretation of data, in the writing of the manuscript, or in the decision to submit the manuscript for publication.

\section{Conflicts of interest}

None.

\section{References}

1. National Institute for Health and Clinical Excellence. Management of chronic obstructive pulmonary disease in adults in primary and secondary care (partial update). 2010. Available from: http://guidance.nice.org.uk/CG101.

2. Global Initiative for Chronic Obstructive Lung Disease. Global Strategy for the Diagnosis, Management, and Prevention of Chronic Obstructive Pulmonary Disease: Update. 2008

3. World Health Organisation. Global Burden of Disease. 2009. Available from: http://www.who.int/healthinfo/global_burden_disease/.

4. Burney P, Jarvis D. The burden of COPD in the UK. NHS Evidence - respiratory. 2006. Available from: http://www.library.nhs.uk/RESPIRATORYNiewResource. aspx? resID=187247

5. Britton M. The burden of COPD in the U.K.: results from the Confronting COPD 
J Upton et al.

Survey. Respir Med 2003;97(Suppl):CS71-9. http://dx.doi.org/10.1016/S09546111(03)80027-6

6. Francke $A$, Smit $M$, Veer $A$ de, Mistiaen P. Factors influencing the implementation of clinical guidelines for health care professionals: a systematic meta-review. BMC Med Inform Decis Mak 2008;8:38. http://dx.doi.org/10.1186/1472-6947-8-38

7. Huang $\mathrm{H}-\mathrm{C}$, Lin $\mathrm{W}-\mathrm{C}$, Lin J-D. Development of a fall-risk checklist using the Delphi technique. J Clin Nurs 2008;17:2275-83. http://dx.doi.org/ 10.1111/j.1365-2702.2008.02337.x

8. Distler $\mathrm{O}$, Behrens F, Pittrow D, et al. Defining appropriate outcome measures in pulmonary arterial hypertension related to Systematic sclerosis: a Delphi consensus study with cluster analysis. Arthritis Rheum 2008;59(6):867-75. http://dx.doi.org/10.1002/art.23718

9. Fink A, Kosecoff J, Chassin M BR. Consensus methods: characteristics and guidelines for use. Am J Public Health 1984;74(9):979-83. http://dx.doi.org/10.2105/AJPH.74.9.979

10. Keeney S, Hasson F MH. Consulting the oracle: ten lessons from using the
Delphi technique in nursing research. J Adv Nurs 2006;53(2):205-12. http://dx.doi.org/10.1111/j.1365-2648.2006.03716.x

11. Jones J, Hunter D. Qualitative research: Consensus methods for medical and health services research. BMJ 1995;311:376-80.

12. Powell C. The Delphi technique: myths and realities. J Adv Nurs 2003;41(4):376-82. http://dx. doi.org/10.1046/j.1365-2648.2003.02537.x

13. Clayton MJ. Delphi: a technique to harness expert opinion for critical decision -making tasks in education. Educ Psychol 1997;17(4):373-86. http://dx.doi.org/10.1080/0144341970170401

14. Jones P, Harding G, Wiklund I, Berry P, Leidy N. Improving the process and outcome of care in COPD: development of a standardised assessment tool. Prim Care Respir J 2009; 18(3):208-15. http://dx.doi.org/10.4104/pcrj.2009.00053

15. Yang IA, Fong K, Sim EH A, Black PN, Lasserson TJ. Inhaled corticosteroids for stable chronic obstructive pulmonary disease. Cochrane Database of Systematic Reviews 2007, Issue 2. Art. No.: CD002991. http://dx.doi.org/10.1002/14651858.CD002991.pub2

Available online at http://www.thepcrj.org

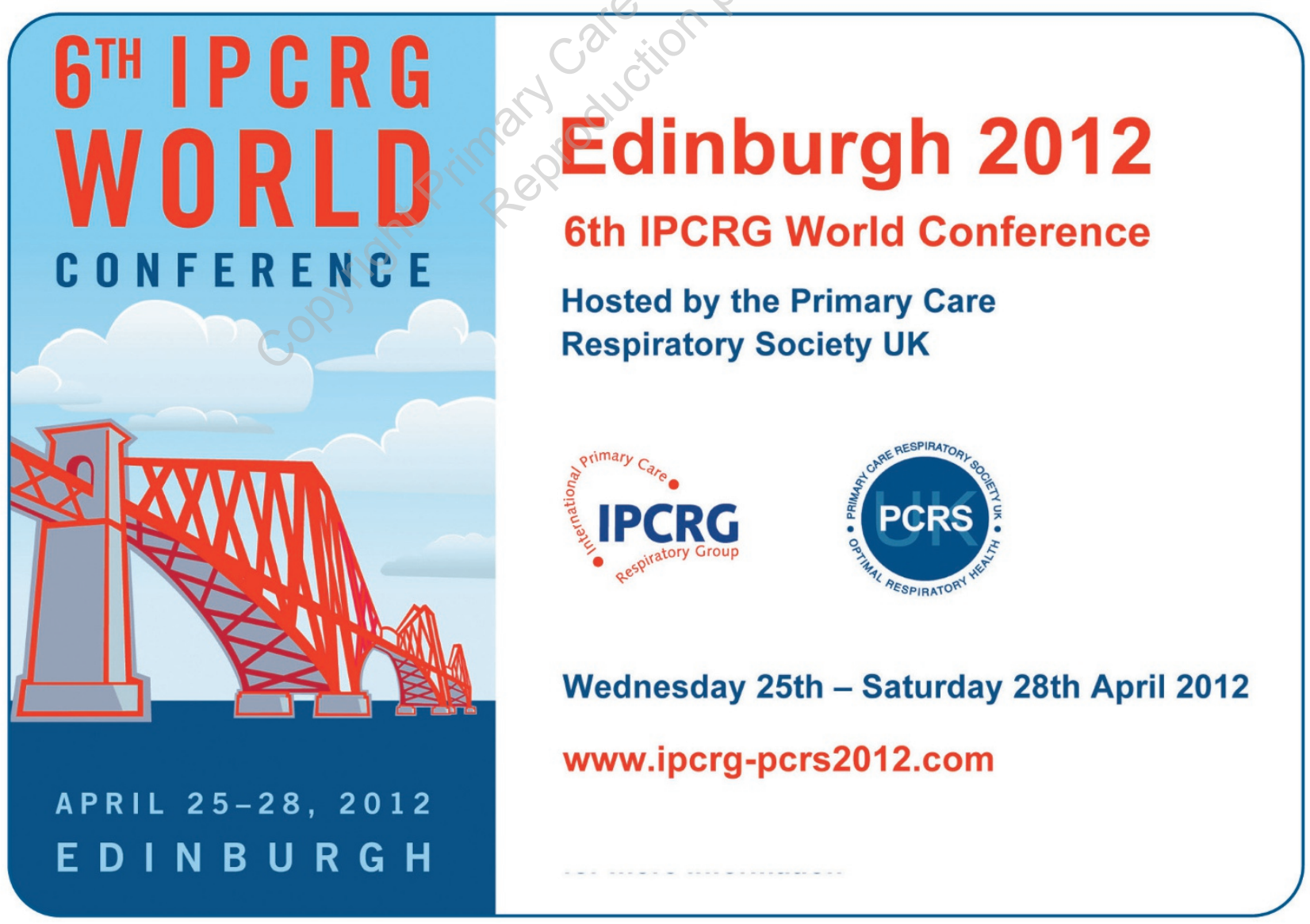


Appendix 1. List of national COPD guideline committees.

- British Thoracic Society Consortium

- COPD National Service Framework

- Improving and Integrating Health Services in the NHS; National Institute for Health and Clinical Excellence

- Global Initiative for COPD

- National COPD Resources and Outcomes Project

- The Primary Care Respiratory Society UK (formerly the General Practice Airways Group) 
J Upton et al.

Appendix 2. Criteria submitted in Round 1 by panel but excluded from Round 2.

Not directly related to changing or initiating COPD treatment

- New onset ankle oedema

- Increasing ankle oedema

- Fluid retention

- Depression

- Anxiety

- Social isolation

- Change in psychological well-being

- Mood changes

- Change in appetite

- Increased lethargy/lack of energy

- Increase in exacerbations

- Two or more exacerbations in a year

- Future risk of exacerbations

- Hospital admissions

- Frequent antibiotic/steroid use 